\title{
Herdian \& Sri Lestari | Ketidakjujuran Akademik KETIDAKJUJURAN AKADEMIK PADA MAHASISWA CALON GURU PROGRAM STUDI PENDIDIKAN ANAK USIA DINI
}

\author{
Herdian \& Sri Lestari \\ herdian@ump.ac.id \\ Universitas Muhammadiyah Purwokerto \\ Universitas Muhammadiyah Surakarta
}

\begin{abstract}
Abstrak
Menjadi seorang guru harus memiliki karakter positif, salah satunya adalah kejujuran. Kejujuran dapat diketahui berdasarkan perilaku akademik selama seorang menjadi mahasiswa. Bahkan, saat ini ada banyak perilaku tidak jujur pada calon pendidik, terutama pada mahasiswa program pendidikan anak usia dini. Tujuan penelitian ini untuk mendeskripsikan perilaku akademik, khususnya ketidakjujuran akademik pada mahasiswa program pendidikan anak usia dini di Universitas X di Jawa Tengah, Indonesia. Fokus penelitian pada bentuk perilaku tidak jujur saat mengerjakan tugas, UTS dan UAS, dan faktor penyebab ketidakjujuran yang terjadi. Penelitian ini menggunakan pendekatan kualitatif fenomenologi dengan alat pengumpulan data dengan wawancara mendalam. Subjek penelitian adalah 4 mahasiswa pada semester 7 yang mengambil mata kuliah di Program Studi Pendidikan Guru dan Pendidikan Anak Usia Dini. Hasil penelitian menunjukkan bahwa bentuk ketidakjujuran akademik pada mahasiswa calon pendidik guru anak usia dini yaitu meminta jawaban, meminta inti sari dari jawaban, melihat jawaban (tanpa diketahui oleh teman), membawa contekan dan mencari jawaban di internet. Faktor ketidakjujuran akademik disebabkan oleh soal yang keluar saat ujian tidak dipelajari atau tidak sesuai dengan apa yang dipelajari saat belajar, tidak tahu jawaban, tidak memahami materi yang disampaikan saat perkuliahan dan belajar yang tidak maksimal.
\end{abstract}

Kata kunci: Ketidakjujuran Akademik, Calon Guru, Karakter. 


\section{Herdian \& Sri Lestari | Ketidakjujuran Akademik}

\section{Abstract}

Being a teacher must have a positive character, one of which is honesty. Honesty can be known based on academic behavior during a student. In fact, there are currently many dishonest behaviors in prospective educators, especially in early childhood education program students. The purpose of this study is to describe academic behavior, especially academic dishonesty in students of early childhood education programs at University $X$ in Central Java, Indonesia. The focus of research is on forms of dishonest behavior when working on Tasks, Middle Semester Exams and final semester examinations, and the causes of dishonesty occur. This study uses a phenomenological qualitative approach with a data collection tool with in-depth interviews. The research subjects were 4 students in the 7th semester who took courses in the Teacher Education Study Program and Early Childhood Education. The results showed that the form of academic dishonesty in prospective students of early childhood teacher educators was asking for answers, asking for the essence of answers, seeing answers (without being known by friends), bringing cheats and searching for answers on the internet. Academic dishonesty factor is caused by the question that comes out when the exam is not studied or not in accordance with what is learned when studying, does not know the answer, does not understand the material delivered during lectures and learning is not optimal.

Keywords: Academic Dishonesty, Prospective Educator, character 


\section{Herdian \& Sri Lestari | Ketidakjujuran Akademik}

\section{Latar Belakang Masalah}

Sistem pendidikan di Indonesia diatur dalam UU no 20 tahun 2003, didalamnya mencakup salah satu pasal yang menjelaskan tentang tujuan pendidikan yaitu:

"Pendidikan nasional berfungsi mengembangkan kemampuan dan membentuk watak serta peradaban bangsa yang bermartabat dalam rangka mencerdaskan kehidupan bangsa, bertujuan untuk berkembangnya potensi peserta didik agar menjadi manusia yang beriman dan bertakwa kepada Tuhan Yang Maha Esa, berakhlak mulia, sehat, berilmu, cakap, kreatif, mandiri, dan menjadi warga negara yang demokratis serta bertanggung jawab" (UU no. 20 Tahun 2003)

Mengambil intisari yang berkaitan dengan karakter dalam penjelasan tujuan pendidikan tersebut, akhlak mulia menjadi sorotan utama sebagai dasar dalam menerapkan pendidikan berbasis karakter. Salah satu karakter penting dalam pendidikan adalah kejujuran. Jujur adalah mengatakan suatu kebenaran atau apa adanya. Istilah kejujuran dalam konteks pendidikan biasanya diatur dalam academic integrity. Setiap lembaga pendidikan memiliki pengaturan terkait academic integrity masing-masing. Umumnya aturan tersebut digunakan untuk mengatur bagaimana pelaksanaan pendidikan yang baik.

Meskipun nilai kejujuran telah diatur dalam academic integrity masing-masing institusi, praktek ketidakjujuran masih lazim dilakukan di dalam kelas di seluruh negara (Marshall \& Varnon). Di Indonesia, ketidakjujuran telah diteliti mulai dari jenjang Sekolah Dasar (Fredrika, 2013), Sekolah Menengah Pertama (Lestari \& Asyanti, 2015), Sekolah Menengah Atas (Ungusari, 2015) dan Peguruan Tinggi (Herdian \& Lestari, 2016). Selain itu ketidakjujuran akademik yang melibatkan institusi yaitu adanya wisuda ilegal. Wisuda ilegal yang sempat menjadi sorotan publik, terjadi di salah satu universitas di Jawa Barat, Indonesia. Berdasarkan informasi yang diperoleh dari koran online (https://nasional.tempo.co) ijazah yang dikeluarkan oleh pendidikan tinggi tersebut diperjual belikan dengan harga 15 juta 


\section{Herdian \& Sri Lestari | Ketidakjujuran Akademik}

rupiah. Praktek ketidakjujuran diatas menggambarkan bahwa integritas akademik di Indonesia cukup mengkhawatirkan jika tetap dibiarkan terjadi. Terlebih Ketidakjujuran akademik merupakan fenomena moral (Colnerul \& Rosander, 2009).

Moeck (2002) megatakan bahwa ketidakjujuran akademik adalah penyalahgunaan materi akademik dengan menghancurkan atau mengubah bagian-bagian konten. Diperjelas oleh Cizek (2003) bahwa ketidakjujuran akademik digolongkan kedalam 3 kategori yaitu (1) memberi, meminta, atau menerima informasi, (2) menggunakan bahan terlarang, (3) memanfaatkan kelemahan orang, prosedur, atau proses untuk mendapatkan keuntungan dalam pekerjaan terkait akademik. Terkait dengan definisi ketidakjujuran akademik Anderman dan Murdock (2011) menjelaskan 3 perspektif yang menjelaskan terjadinya fenomena ketidakjujuran akademik, yaitu perspektif pembelajaran, kecurangan adalah strategi yang berfungsi sebagai jalan pintas kognitif. Perspektif perkembangan, kecurangan dapat terjadi dalam kuantitas dan kualitas yang berbeda tergantung pada tingkat perkembangan kognitif, sosial, dan moral siswa. Perspektif motivasi, pelajar menyatakan banyak alasan yang berbeda-beda untuk terlibat dalam kecurangan akademik.

Hetherington dan Feldman (1964) mengatakan setidaknya ada 4 tipe ketidakjujuran akademik yang dilakukan yaitu social active, social passive, individualistic opportunistic dan independent planned. Social active adalah kecurangan yang dilakukan dengan cara meminta, menanyakan, mengambil jawaban dari orang lain secara aktif. Social passive adalah kecurangan yang dilakukan dengan membiarkan atau bahkan memberikan bantuan jawaban secara suka rela. Individualistic opportunistic adalah kecurangan yang dilakukan mandiri secara impulsive dan tiba-tiba tanpa adanya perencanaan. Independent planned adalah kecurangan yang mengandalkan diri sendiri untuk dilakukan secara sengaja dan terencana pada saat ujian.

Penelitian sebelumnya melaporkan bahwa ketidakjujuran akademik didominasi oleh faktor motivasional (Handayani \& 


\section{Herdian \& Sri Lestari | Ketidakjujuran Akademik}

Baridwan, 2013; Nursani \& Irianto; 2013). Dijelaskan oleh McCabe (1999) motivasi umum yang ditemukan dalam praktik ketidakjujuran akademik dilatarbelakangi oleh adanya tekanan untuk mendapatkan nilai yang lebih tinggi, keinginan untuk unggul, kurangnya persiapan dan tekanan untuk mendapatkan pekerjaan setelah selesai studi. Penelitian lain telah melaporkan faktor lainnya seperti adanya bukti kuat dari apa yang disebut efek teman sebaya pada kecurangan siswa (Carrell et al., 2008; McCabe dan Trevino, 1993; OLeary dan Pangemanan, 2007; McCabe et al., 2001; McCabe dan Trevino, 1997). Faktor-faktor lainnya mengatakan ketidakjujuran akademik lebih dikarenakan adanya kesempatan dan rasionalisasi (Eriskawarti \& Januarti, 2017).

Berdasarkan paparan studi hasil penelitian di Indonesia dan studi literatur terkait penelitian terkini. Penelitian ini tertarik untuk lebih dalam meneliti ketidakjujuran akademik pada calon guru. Mahasiswa yang sedang mengambil program studi di Fakultas Keguruan dan Ilmu Pendidikan disebut sebagai calon pendidik, karena prospek lulusannya akan terserap banyak bekerja di lembaga pendidikan. Pendidikan Guru Pendidikan Anak Usia Dini (PG PAUD) merupakan salah satu Program studi yang mencetak calon guru. Menjadi guru PAUD dapat dikatakan jauh lebih sulit pekerjaannya dibandingkan dengan guru di jenjang lainnya. Hal ini dikarenakan kemampuan guru dituntut lebih sabar, cekatan, cerdas, komunikatif dan yang lebih penting lagi sebagai teladan bagi peserta didiknya yang masih anak-anak. Menjadi guru teladan mengacu pada UU no 14 tahun 2015 yang berkaitan dengan akhlak mulia, salah satunya kejujuran. Nilai kejujuran pada seorang guru harus menjadi karakter sejak awal. Pengaplikasian dari kejujuran guru dapat dilihat pada saat kuliah diperguruan tinggi. 


\section{Herdian \& Sri Lestari | Ketidakjujuran Akademik}

\section{Metode Penelitian}

\section{Desain Penelitian}

Penelitian ini metode yang digunakan adalah kualitatif karena hasilnya dijabarkan secara eskploratif. Sedangkan pendekatan yang digunakan adalah fenomenologi karena mengungkap pegalaman mahasiswa sebagai calon pendidik dalam menghadapi situasi yang dimungkinkan untuk tidak jujur dalam mengerjakan tugas-tugas kuliah.

\section{Partisipan Penelitian}

Informan dalam penelitian ini yaitu 4 mahasiswa aktif semester 7 yang sedang kuliah di Program Studi Pendidikan Anak Usia Dini Universitas X di Purwokerto, Jawa Tengah.

\section{Instrumen Penelitian}

Alat pengumpulan data menggunakan wawancara mendalam (indepth interview), karena menggali suatu fenomena secara mendalam.

\section{Analisis Data}

Analisis data yang digunakan dalam penelitian ini yaitu dengan analisis interaktif dengan tahap-tahapnya sebagai berikut; (1) Pengumpulan data, (2) Reduksi data (3) Penyajian data hasil penelitian dan, (4) Menarik kesimpulan atau verifikasi.

\section{Hasil Penelitian}

Mengacu pada tujuan penelitian ini yaitu mendeskripsikan bentuk-bentuk ketidakjujuran akademik pada saat mengerjakan tugas, ujian tengah semester dan ujian akhir semester serta faktor-faktor yang melatarbelakangi perilaku ketidakjujuran tersebut muncul. Secara singkat dijelaskan sebagai berikut; 
Herdian \& Sri Lestari | Ketidakjujuran Akademik Bentuk Ketidakjujuran akademik pada saat mengerjakan tugas

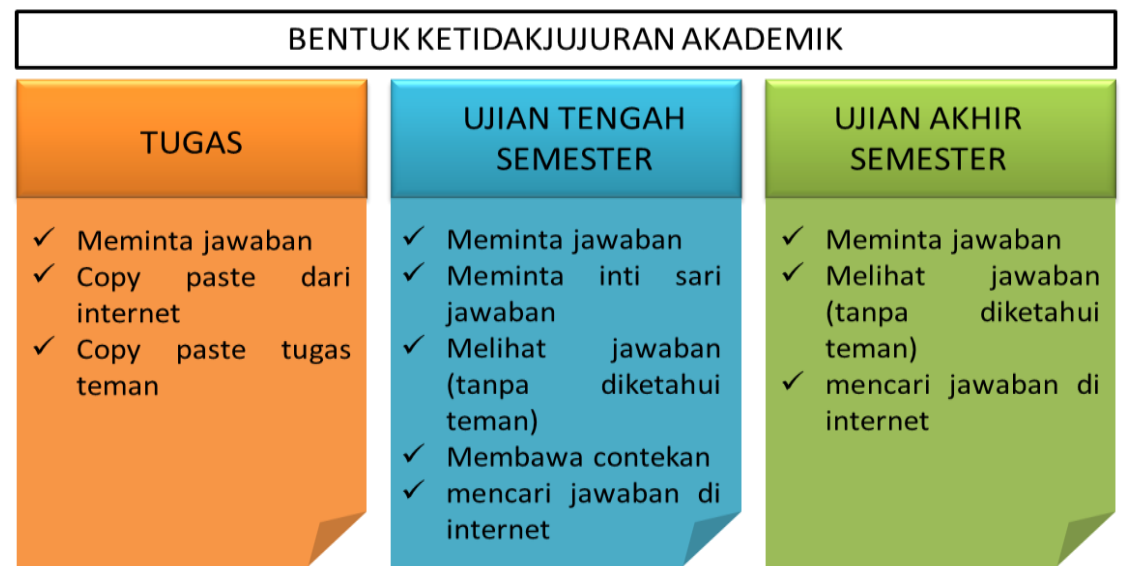

Gambar 1. Bentuk Ketidakjujuran Akademik

Ketidakjujuran akademik bayak dilakukan oleh mahasiswa dalam bentuk meminta jawaban, copy paste dari internet dan mengcopy paste tugas teman. Bentuk ketidakjujuran akademik pada saat mengerjakan ujian tengah semester, yaitu meminta jawaban, meminta inti sari dari jawaban, melihat jawaban (tanpa diketahui oleh teman), membawa contekan dan mencari jawaban di internet. Bentuk ketidakjujuran akademik pada saat mengerjakan ujian akhir semester meliputi meminta jawaban, melihat jawaban (tanpa diketahui oleh teman dan mencari jawaban di internet. Lebih jelas dipaparkan pada gambar 1.

Berdasarkan hasil penelitian ini, bentuk ketidakjujuran akademik yang dilakukan oleh mahasiswa calon pendidik disetiap aktivitas pengerjaan tugas, ujian tengah semester dan ujian akhir semester memiliki kesamaan bentuk, terutama meminta jawaban. Bentuk ketidakjujuran akademik berdasarkan tipe ketidakjujuran Hetherington dan Feldman (1964) perilaku ketidakjujuran akademik dengan meminta jawaban merupakan tipe ketidakjujuran akademik social active. Ketidakjujuran tersebut dilakukan dengan cara meminta, menanyakan, mengambil jawaban dari orang lain secara aktif. Lebih jelas tipe ketidakjujuran 


\section{Herdian \& Sri Lestari | Ketidakjujuran Akademik}

yang digunakan mahasiswa dapat dilihat pada gambar 2 .

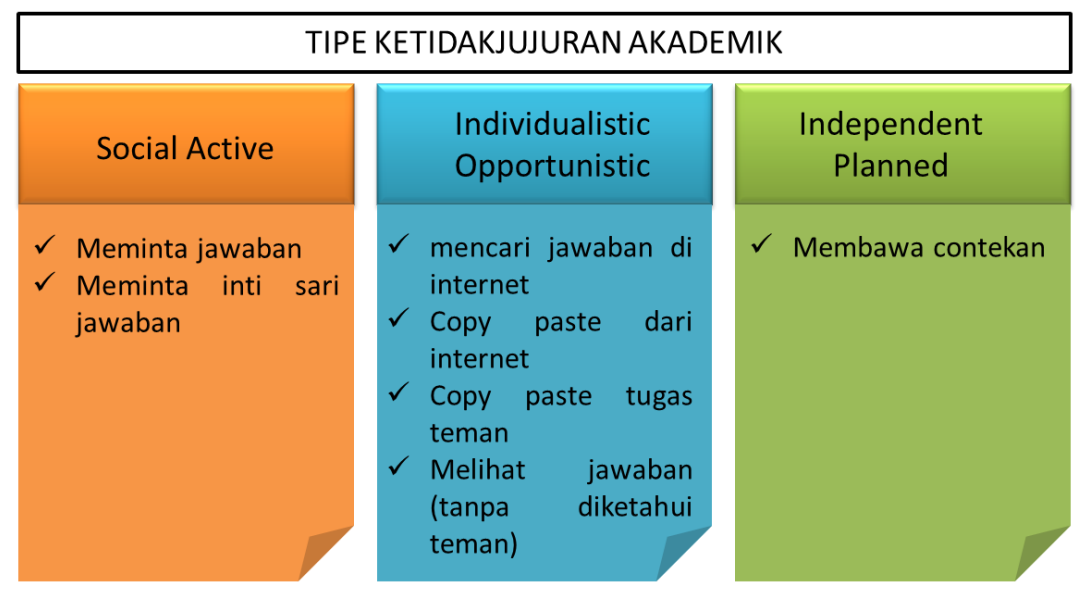

Gambar 2. Tipe Ketidakjujuran Akademik

\section{Faktor penyebab ketidakjujuran}

Ketidakjujuran akademik dilatarbelakangi oleh banyak faktor, berdasarkan hasil penelitian ini, ketidakjujuran akademik dilatarbelakangi oleh 4 faktor yaitu soal yang keluar saat ujian tidak dipelajari atau tidak sesuai dengan apa yang diplajari saat belajar, tidak tahu jawaban, tidak memahami materi yang disampaikan saat perkuliahan dan belajar yang tidak maksimal. Lebih jelas dipaparkan dalam tabel 1 .

Tabel 1. Faktor Penyebab Ketidakjujuran Akademik

\begin{tabular}{|l|l|}
\hline Informan & Faktor penyebab ketidakjujuran akademik \\
\hline P1 & $\begin{array}{l}\text { "Ya karna soalnya yaitu yang gak dipelajari, itu sih } \\
\text { menerut aku ..." }\end{array}$ \\
\hline P2 & $\begin{array}{l}\text { "Penyebab saya tanya keteman karena saya benar- } \\
\text { benar tidak tahu jawabannya, sudah buntu, lupa, dan } \\
\text { biar kejawab semua dan jawabannya gak ada yg } \\
\text { kosong" }\end{array}$ \\
\hline P3 & $\begin{array}{l}\text { "karena blm bisa memahami tentang mata kuliah yg } \\
\text { di ajarkan dosen makanya saya melakukan ketidak } \\
\text { jujuran terutama pada mata kuliah statistik yg saya }\end{array}$ \\
\hline
\end{tabular}


Herdian \& Sri Lestari | Ketidakjujuran Akademik

\begin{tabular}{|l|l|}
\hline \multicolumn{1}{|l|}{ P4 } & "Kalm paham" \\
& saya bisa menjawab pertanyaan dari soal-soal. \\
& Terkadang saya belajar kurang maksimal sehingga \\
& tidak semua materi saya kuasai dan pahami" \\
\hline
\end{tabular}

Sumber: hasil wawancara dengan informan

Berdasarkan perspektif pembelajaran, faktor penyebab ketidakjujuran akademik dalam penelitian ini, mahasiswa menggunakan strategi ketidakjujuran sebagai jalan pintas kognitif (Anderman \& Murdock, 2011). Hal ini dikarenakan ketidakmampuannya dalam berpikir untuk memperoleh jawaban. Hasil penelitian ini selaras dengan hasil penelitian McCabe (1999) yang mengatakan kurangnya persiapan menjadi salah satu faktor penyebab terjadinya ketidakjujuran akademik.

\section{Kesimpulan}

Berdasarkan hasil penelitian ini, bentuk ketidakjujuran akademik pada mahasiswa calon pendidik guru anak usia dini yaitu meminta jawaban, meminta inti sari dari jawaban, melihat jawaban (tanpa diketahui oleh teman), membawa contekan dan mencari jawaban di internet. Faktor ketidakjujuran akademik disebabkan oleh yaitu soal yang keluar saat ujian tidak dipelajari atau tidak sesuai dengan apa yang diplajari saat belajar, tidak tahu jawaban, tidak memahami materi yang disampaikan saat perkuliahan dan belajar yang tidak maksimal. Peneliti menyadari banyakhal yang belum diteliti dari ketidakjujuran akademik pada calon pendidik. Oleh sebab itu, peneliti menyarankan untuk melakukan penelitian lanjutan dengan berbagai pendekatan dan metode yg berbeda

\section{Saran-saran}

\section{Saran Teknis}

Penelitian ini hanya menggunakan indepth interview, untuk peneliti selanjutnya agar dapat menggunakan berbagai pendekatan dan alat pengumpulan data lainnya untuk 


\section{Herdian \& Sri Lestari | Ketidakjujuran Akademik}

memperkaya hasil dan keilmuan khususnya dalam bidang karakter.

\section{Saran Praktis}

Hasil penelitian ini dapat dijadikan dasar untuk menentukan kebijakan terkait peraturan akademik untuk meningkatkan integritas akademik dikampus, selain itu dapat dijadikan sebagai bahan untuk dilakukan intervensi untuk mengurangi perilaku tidakjujur dalam akademik.

\section{Daftar Pustaka}

Anderman, E. M., \& Murdock, T. B. (Eds.). (2011). Psychology of academic cheating. Elsevier.

Cizek, G. J. (2003). Detecting and preventing classroom cheating: Promoting integrity in assessment. Corwin Press

Colnerud, G., \& Rosander, M. (2009). Academic dishonesty, ethical norms and learning. Assessment \& Evaluation in Higher Education, 34(5), 505-517.

Carrell, S.E., Malmstrom, F.V., West, J.E., (2008). Peer effects in academic cheating. J. Hum. Resour. 43 (1), 173-207.

Eriskawati, E., \& Januarti, I. (2017). The Influence Of Relativism, Idealism, And Gender On The Students'academic Cheating Behaviour. Jurnal Dinamika Akuntansi, 8(1), 73-83.

Fredrika, M. E., \& Prasetyawati, W. (2013). Gambaran kecurangan Akademik pada Siswa Kelas 6 Sekolah Dasar. Skripsi (tidak diterbitkan) jakarta Fakultas Psikologi Universitas Indonesia.

Handayani \& Baridwan. (2013). Faktor-faktor yang mempengaruhi perilaku ketidakjujuran akademik: modifikasi theory of planed behaviour. Jurnal Ilmiah Mahasiswa FEB, 2 (1) dipetik Agustus 3, 2015 dari http://portalgaruda.org/?ref=browse\&mod=viewarticle \& article $=189226$ 


\section{Herdian \& Sri Lestari | Ketidakjujuran Akademik}

Hetherington, E. M., \& Feldman, S. E. (1964). College cheating as a function of subject and situational variables. Journal of Educational Psychology, 55(4), 212.

Marshall, L. L., \& Varnon, A. W. (2017). Attack on Academic Dishonesty: What" Lies" Ahead? Journal of Academic Administration in Higher Education, 13(2), 31-40.

Lestari, S., \& Asyanti, S. (2015). Apakah siswa SMP berperilaku jujur dalam situasi ulangan? The 2nd University Research Coloquium 2015 ISSN 2407-9189

McCabe, D.L., Trevino, L.K., (1993). Academic dishonesty: Honor codes and other contextual influences. J. Higher Educ. 522538.

McCabe, D.L., Trevino, L.K., (1997). Individual and contextual influences on academic dishonesty: A multicampus investigation. Res. Higher Educ. 38 (3), 379-396.

McCabe, D.L., Trevino, L.K., Butterfield, K.D. (2001). Cheating in academic institutions: A decade of research. Ethics Behav. 11 (3), 219-232.

Moeck, P. G. (2002). Academic Dishonesty: Cheating among Community College Students. Community College Journal of Research and Practice, 26, 479-491

OLeary, C., Pangemanan, G., (2007). The effect of groupwork on ethical decisionmaking of accountancy students. J. Bus. Ethics 75 (3), 215-228.

Ungusari, E. (2015). Kejujuran dan Ketidakjujuran Akademik pada Siswa SMA yang Berbasis Agama. Skripsi (tidak diterbitkan). Fakultas psikologi, Universitas Muammadiyah Surakarta). Psikologi Universitas Muhammadiyah Surakarta 